\title{
Influence of Zinc and Ammonium Compounds on the Growth and Characterisation of L Alanine NLO Crystals
}

\author{
P. Sagunthala ${ }^{a, *}$, V. Veeravazhuthi ${ }^{b}$, P. Yasotha $^{a}$ And P. Hamalatha ${ }^{c}$ \\ ${ }^{a}$ Department of Physics, Sri Vasavi College, Erode, Tamilnadu, India \\ ${ }^{b}$ Department of Physics, PSG College of Arts and Science, Coimbatore, Tamilnadu, India \\ ${ }^{c}$ Department of Physics, Govt. Arts College, Coimbatore, Tamilnadu, India
}

(Received April 15, 2016; in final form August 1, 2018)

\begin{abstract}
Single crystals of zinc sulphate monohydrate L alanine and ammonium sulphate L alanine had been grown by slow evaporation technique. The crystalline nature and unit cell parameters of the grown crystals were determined using powder and single crystal X-ray diffraction. The grown crystals retained the orthorhombic crystal system. UV-vis transmittance and second harmonic generation studies were performed to analyze the optical behaviour of the crystals. The Fourier transform infrared spectra were recorded in the region $4000-400 \mathrm{~cm}^{-1}$ to identify the presence of functional groups. Thermogravimetric analysis helped to determine the percentage of decomposition of the sample at different temperatures as well as the thermal stability of the compound. Mechanical and electrical properties of grown crystals were ascertained through the Vickers micro hardness and dielectric studies.
\end{abstract}

DOI: 10.12693/APhysPolA.134.467

PACS/topics:

\section{Introduction}

Nonlinear optical (NLO) crystals have become the area of current research because of its vital applications in various areas like optical modulation, switching, logic, frequency shifting, and data storage in telecommunications and in signal processing $[1,2]$. The development of efficient NLO crystals for visible and ultraviolet region is necessary for both laser spectroscopy and laser processing. Melting point and boiling point of $d$ block elements are high and they are hard in nature. Transition metal atom has partially filled $d$ subshell. Crystals made from transition metal compounds are non-stoichiometric in nature due to variable valence and defects in solid structure. The atoms of small elements like $\mathrm{H}_{2}, \mathrm{~B}, \mathrm{C}$, $\mathrm{N}$, etc., fit into the interstitial sites of transition metal lattices. These interstitial compounds resemble the parent transition metal in chemical properties, but differ in physical properties such as hardness and electrical properties [3]. These materials are used for parts requiring considerable fabrication properties such as resistance to corrosion, ease of fabrication (casting, rolling, and forging), strength, weight, colour, thermal and electrical conductivity [4]. Hence, recent researches are concentrated on inorganic materials added with organic counter parts due to their large nonlinearity, high resistance to laser induced damage, low angular sensitivity, and good mechanical hardness [5]. Metal organic compounds have considerable high nonlinear coefficient, stable physico chemical properties and better mechanical indentation [6]. Studies on organo-metallic complexes proved that the formation

*corresponding author; e-mail: saguphy@gmail.com of a co-ordination bond can improve their melting point and mechanical properties [7-10]. In our present study, with an aim of growing mixed crystals of $\mathrm{L}$ alanine, zinc sulphate monohydrate L alanine (ZLA) and ammonium sulphate L alanine (ALA) single crystals had been grown by slow evaporation at room temperature and the crystals were subjected to various characterizations.

\section{Materials and methods}

Saturated solutions of $\mathrm{ZnSO}_{4} \cdot \mathrm{H}_{2} \mathrm{O}(57.7 \mathrm{~g} / 100 \mathrm{ml})$, $\left(\mathrm{NH}_{4}\right)_{2} \mathrm{SO}_{4} \quad(74.4 \quad \mathrm{~g} / 100 \mathrm{ml})$ and $\mathrm{L}$ alanine $(16.72 \mathrm{~g} / 100 \mathrm{ml})($ MERCK) were prepared using doubly distilled water and filtered twice using Whatman No. 1 filter paper to remove dust particles and undissolved materials. The saturated solutions of $\mathrm{ZnSO}_{4} \cdot \mathrm{H}_{2} \mathrm{O}$ and $\mathrm{L}$ alanine were taken in the stoichiometric ratio $3: 1$ $(\mathrm{pH} 5)$ and it was allowed to stir for six hours at room temperature using magnetic stirrer (REMI $1 \mathrm{MLH}$ ) to get good homogeneity. Similarly, saturated solutions of $\left(\mathrm{NH}_{4}\right)_{2} \mathrm{SO}_{4}$ and $\mathrm{L}$ alanine were prepared in the stoichiometric ratio $3: 1(\mathrm{pH} \mathrm{6})$. The beakers containing above solutions were covered with perforated sheet to facilitate slow evaporation of the solvent at room temperature. The solutions gradually attained supersaturation due to evaporation which resulted in nucleation followed by the growth of crystals. Transparent single crystals of ZLA and ALA were harvested after a time span of 33 and 47 days, respectively. The expected chemical reactions are given below:

$$
\begin{aligned}
& \mathrm{ZnSO}_{4}+\mathrm{CH}_{3} \mathrm{CH}\left(\mathrm{NH}_{2}\right) \mathrm{COOH} \rightarrow \\
& \mathrm{NH}_{3}^{+}-\mathrm{CH}-\left(\mathrm{CH}_{3}\right)-\mathrm{COO}^{-} \mathrm{ZnSO}_{4}, \\
& \left(\mathrm{NH}_{4}\right)_{2} \mathrm{SO}_{4}+2 \mathrm{CH}_{3} \mathrm{CH}\left(\mathrm{NH}_{2}\right) \mathrm{COOH} \rightarrow \\
& \quad\left(\mathrm{NH}_{3}^{+}-\mathrm{CH}-\left(\mathrm{CH}_{3}\right)-\mathrm{COONH}\right)_{2} \mathrm{SO}_{4} .
\end{aligned}
$$


The photographs of as grown single crystals of ZLA and ALA are shown in Fig. 1a and b, respectively. The dimensions of the grown single crystals ZLA and ALA were found to be $10 \times 12 \times 7 \mathrm{~mm}^{3}$ and $38 \times 5 \times 6 \mathrm{~mm}^{3}$, respectively.


Fig. 1. Photograph of (a) ZLA, (b) ALA.

\section{Results and discussions}

Various characterisation studies were carried out for the grown crystals and the results are discussed hereunder.

\subsection{Powder X-ray diffraction}

In the present study, finely crushed powder of ZLA and ALA were subjected to powder X-ray diffraction (XRD) analysis. The samples were scanned over the range of $10-70^{\circ}$ at a scan rate of $1^{\circ} / \mathrm{min}$ using Richseifert diffractometer with $\mathrm{Cu} K_{\alpha}(\lambda=1.5406 \AA)$ radiation. The XRD patterns of ZLA and ALA are shown in Fig. 2a and b. XPowder software was utilized to index the peaks. The sharp peaks confirmed the crystalline nature of the grown materials. The change in the peak heights, small change in intensity and the additional peaks of ZLA and ALA samples from that of $\mathrm{L}$ alanine are noticed [11]. This indicates the inclusion additives in the grown ZLA and ALA crystals.

\subsection{Single $X$-ray diffraction}

The as-grown crystals of ZLA and ALA have been subjected to single crystal XRD employing a Bruker AXS diffractometer using Mo $K_{\alpha}$ radiation $(\lambda=0.71073 \AA)$. The single crystal XRD reveals that the crystals ZLA and ALA belong to orthorhombic system. The lattice
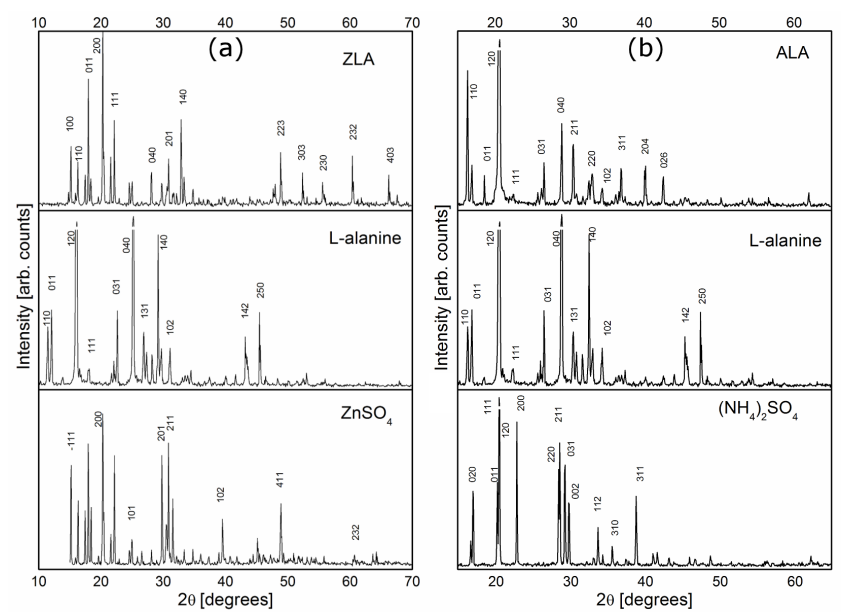

Fig. 2. Powder XRD of (a) ZLA, (b) ALA.

parameter values are given in Table I. It is observed that there is small change in the lattice parameters and cell volume in the grown ZLA and ALA crystals compared to that of $\mathrm{L}$ alanine. The results are in good agreement with the reported values $[12,13]$.

TABLE I

Cell parameters of the grown crystals (all orthorhombic, $\alpha=\beta=\gamma=90^{\circ}$ ).

\begin{tabular}{c|c|c|c|c}
\hline \hline Crystal & $a[\AA]$ & $b[\AA]$ & $c[\AA]$ & Cell volume $\left[\AA^{3}\right]$ \\
\hline ZLA & 6.034 & 12.337 & 5.783 & 430.49 \\
\hline ALA & 6.023 & 12.351 & 5.768 & 429.06 \\
\hline L alanine & 6.032 & 12.343 & 5.784 & 430.09
\end{tabular}

\section{3. $U V$-visible spectral analysis}

The optical transmission spectrum of the grown ZLA and ALA crystals were recorded using Shimadzu UV-vis spectrophotometer between the wavelength ranges of 200 and $800 \mathrm{~nm}$ and is shown in Fig. 3. From the UV transmittance spectrum, it is found that the grown crystals are highly transparent in the wavelength range of 240$800 \mathrm{~nm}$. The cut-off wavelength for ZLA is $220 \mathrm{~nm}$ and ALA is $203.5 \mathrm{~nm}$. The transparency of ZLA is $86 \%$ and that of ALA is $91 \%$. Hence the grown crystals have wide transparency range both in UV and visible region. This is one of the key requirements for NLO crystals [11].

\subsection{Second harmonic generation studies}

The Kurtz and Perry method was employed to measure second harmonic generation (SHG) efficiency of the grown single crystals. The fine-powdered crystals were tightly packed in a microcapillary tube and it served as the sample cell. This cell was mounted in the path of Nd:YAG laser beam of energy $1.9 \mathrm{~mJ} /$ pulse with pulse width of $10 \mathrm{~ns}$ and repetition rate of $10 \mathrm{~Hz}$. The emission of green radiation confirmed the presence of SHG in the grown ZLA and ALA crystals. The SHG efficiency 


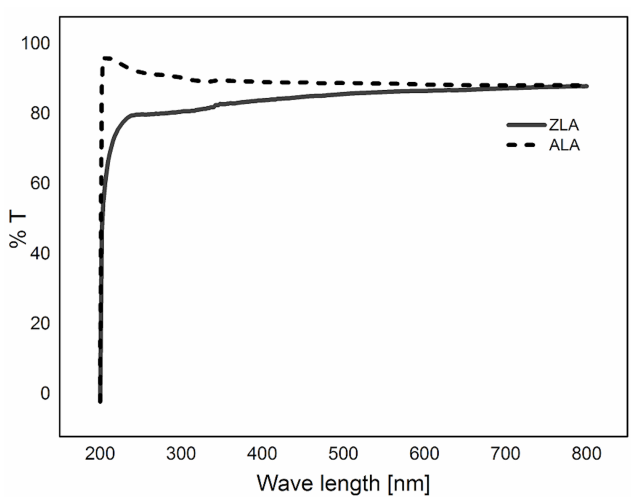

Fig. 3. UV-visible spectrum of grown crystals.

of ZLA and ALA crystals are about $76 \%$ and $70 \%$ of that of KDP respectively which is almost double that of $\mathrm{L}$ alanine $[14,15]$.

\subsection{FTIR spectral analysis}

The infrared spectroscopy is effectively used to identify the functional groups present in the samples. The FTIR spectra of the grown crystals ZLA and ALA were recorded in the frequency region $4000-400 \mathrm{~cm}^{-1}$ using Perkin Elmer spectrometer and are shown in Fig. 4a and $\mathrm{b}$, respectively. Comparative band assignments of grown crystals are given in Table II. For the crystal ZLA the peaks at 2291 and $2252 \mathrm{~cm}^{-1}$ correspond to asymmetric stretching of zinc coordinated $\mathrm{NH}_{2}$ and $\mathrm{COO}^{-}$[16]. The incorporation of sulphur was confirmed in both the crystals ZLA and ALA by the presence of vibrations corresponding to $\mathrm{S}=\mathrm{O}, \mathrm{S}-\mathrm{O}$ and $\mathrm{SO}_{4}^{-}$as shown in Table II [17]. The normal vibration of the free $\mathrm{SO}_{4}^{2-}$ has four internal vibrations, the symmetric stretching mode, the symmetric bending mode, the asymmetric stretching mode, and the asymmetric bending mode [18]. In the grown crystal ZLA, the peak observed at $1010 \mathrm{~cm}^{-1}$ is attributed to the symmetric stretching mode of $\mathrm{SO}_{4}^{2-}$, the peak observed at $486 \mathrm{~cm}^{-1}$ is due to the symmetric bending mode of $\mathrm{SO}_{4}^{2-}$. The bands observed at 624 and $617 \mathrm{~cm}^{-1}$ are due to the asymmetric bending mode of $\mathrm{SO}_{4}^{2-}$ in the grown crystals ZLA and ALA, respectively. The band observed at $1109 \mathrm{~cm}^{-1}$ in ALA is assigned to the asymmetric stretching of $\mathrm{SO}_{4}^{2-}$. Presence of various functional groups corresponding to $\mathrm{N}-\mathrm{H}, \mathrm{NH}_{2}, \mathrm{OH}, \mathrm{C}=\mathrm{O}, \mathrm{C}-\mathrm{H}, \mathrm{C}-$ $\mathrm{N}$ and $\mathrm{C}-\mathrm{C}-\mathrm{N}$ shows the occurrence of $\mathrm{L}$ alanine in the grown crystals. The above assignments agree with the already reported values $[7,17,19]$.

\subsection{Thermal characterization}

Thermogravimetric analysis (TGA) gives information regarding phase transition and different stages of decomposition of the crystal system [20]. The TGA was carried out using a Perkin-Elmer thermal analyzer in nitrogen atmosphere up to $700^{\circ} \mathrm{C}$ at a heating rate of $20^{\circ} \mathrm{C} / \mathrm{min}$.

In the TGA curve of ZLA (Fig. 5a) there are three stages of decomposition of the crystal. In the first stage,
FTIR spectral data of grown crystals.

TABLE II

\begin{tabular}{l|c|c}
\hline \hline \multirow{2}{*}{ Band assignment } & \multicolumn{2}{|c}{ Wave number $\left[\mathrm{cm}^{-1}\right]$} \\
\cline { 2 - 3 } & ZLA & ALA \\
\hline $\mathrm{NH}_{3}^{+}$asymmetric & - & 3126 \\
stretching & & \\
asymmetric stretching & & \\
of $\mathrm{Zn}$ coordinated $^{-}$ & 2291,2252 & - \\
$-\mathrm{NH}_{2}$ and -COO & \\
$\mathrm{CH}_{3}$ & 1357 & 1400 \\
$\mathrm{~N}^{-} \mathrm{H}$ stretching & 1357 & 2067 \\
$\mathrm{~S}=\mathrm{O}$ stretching & 1296 & - \\
$\mathrm{S}-\mathrm{O}$ stretching & 918 & - \\
$\mathrm{SO}{ }_{4}^{2-}$ & $1010,624,486$ & 1109,617 \\
bending vibration & 763 & - \\
mode of $\mathrm{H}_{2} \mathrm{O}$ & & \\
$\mathrm{C}=\mathrm{O}$ symmetric & - & 1400 \\
stretching & 624,540 & 1400,617 \\
$\mathrm{COO}-$ & $1357,1234,918$ & $2361,1400,1109$ \\
$\mathrm{C}-\mathrm{H}$ & 1296 & 1109 \\
$\mathrm{C}-\mathrm{N}$ & 1010 & - \\
$\mathrm{C}-\mathrm{C}-\mathrm{N}$ &
\end{tabular}


Fig. 4. FTIR spectrum of (a) ZLA, (b) ALA.

there is a weight loss of about $23 \%$ in the temperature range of $77^{\circ} \mathrm{C}$ to $100^{\circ} \mathrm{C}$ due to dehydration of the crystal [17]. It is observed that there is no appreciable weight loss in the temperature range of $100^{\circ} \mathrm{C}$ to $230{ }^{\circ} \mathrm{C}$. Nearly $10 \%$ of the sample is gradually decomposed in the second stage due to the liberation of $\mathrm{L}$ alanine present in the compound from $230^{\circ} \mathrm{C}$ to $300^{\circ} \mathrm{C}$. The remaining 
$67 \%$ of the sample is stable up to $700{ }^{\circ} \mathrm{C}$. From this, it is concluded that the crystal ZLA can retain texture up to $77^{\circ} \mathrm{C}$ and hence its application can be extended up to $77^{\circ} \mathrm{C}$.
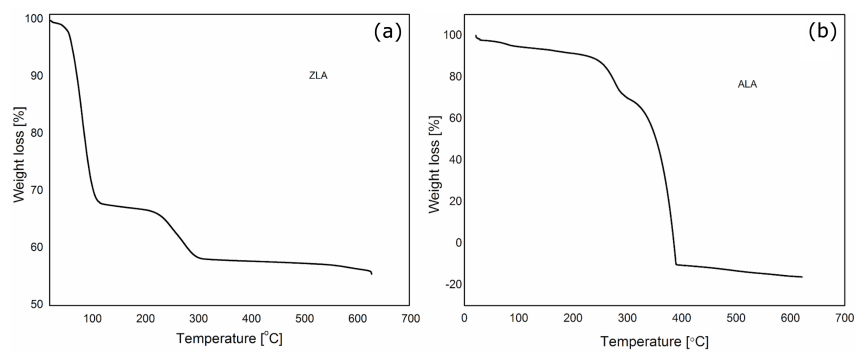

Fig. 5. TGA spectrum of (a) ZLA, (b) ALA.

Figure 5b shows the TGA curve of the grown crystal ALA. It is noticed that there is a negligible weight loss up to $240{ }^{\circ} \mathrm{C}$. About $30 \%$ of the sample got decomposed due to the liberation of volatile substances at $305^{\circ} \mathrm{C}$. The major weight loss occurred at $305^{\circ} \mathrm{C}$ and the remaining $70 \%$ of the sample got completely decomposed at the temperature of $392{ }^{\circ} \mathrm{C}$. Form the graph it is obvious that the grown crystal ALA is highly stable up to $240^{\circ} \mathrm{C}$ which indicates that the crystal is a potential candidate for NLO applications $[21,22]$. Since ALA crystal can retain texture up to $240^{\circ} \mathrm{C}$, it is more stable than the other semi-organic crystals like L-alanine cadmium chloride $\left(110^{\circ} \mathrm{C}\right)$, triallyl thiourea cadmium chloride $\left(101^{\circ} \mathrm{C}\right)$, triallyl thiourea cadmium bromide $\left(97^{\circ} \mathrm{C}\right)$, triallyl thiourea mercury chloride $\left(133^{\circ} \mathrm{C}\right)$ and allyl thiourea mercury bromide $\left(125^{\circ} \mathrm{C}\right)[23]$.

\subsection{The Vickers microhardness studies}

The hardness of the crystals depends on type of chemical bonding, lattice energy, the Debye temperature, heat of formation, and inter atomic spacing. Microhardness test provides information about the mechanical properties like elastic constants, yield strength, resistance, and pressure of the materials. The Vickers hardness test is the most common and reliable method for hardness measurement of single crystals [24]. The microhardness of the grown crystals was measured using a Shimadzu microhardness tester with a diamond indenter. In the present work, well polished crystals ZLA and ALA were mounted on a platform of the microhardness tester and indentations were made on the grown crystals for three loads 25,50 , and $100 \mathrm{~g}$ and indentation time given was $10 \mathrm{~s}$. The length of the two diagonals of diamond indenter was measured and the average was found out. For a particular load, at least two well defined indentations were considered and the average value $(d)$ was calculated.

The Vickers hardness number was determined using the expression

$$
H_{V}=1.8544 P / d^{2} \text {, }
$$

where $P$ is the applied load, $d$ is the average diagonal length of the indentation marks and the result is plotted
(Fig. 6a). From the graph, the hardness value increased with the increase of load and hence the grown crystals exhibited the reverse indentation size effect (RISE) [25]. According to the Meyer law, the relation between the load and size of indentation is $P=k_{1} d^{n}$, where $k_{1}$ is the material constant, $n$ is the Meyer index or work hardening coefficient. The above relation shows that $H_{V}$ should increase with load if $n>2$ and decrease with load when $n<2$. The plot of $\log P$ versus $\log d$ is shown in Fig. $6 \mathrm{~b}$. The slope of the line (the Mayer index $n$ ) for the grown crystal of ZLA is 3.61 and that of ALA is 2.32. From this we can say that the grown crystals ZLA and ALA belong to soft materials [26]. Elastic stiffness constant $\left(C_{11}\right)$ was calculated by the Wooster empirical relation as

$$
C_{11}=H_{V}^{7 / 4} \text {. }
$$

Hardness number and stiffness constant values of grown crystals for different loads are given in Table III. From the table, it is clear that the stiffness constant increases with increase in load. Hence the high value of $C_{11}$ indicates that the binding forces between the ions are quite strong [25, 27]. Hence it is confirmed that the mechanical properties like hardness number and stiffness constant are changed considerably for the grown crystals ZLA and ALA compared to pure L alanine single crystals. This change in the hardness can be attributed due to the incorporation of impurities in the lattice of L-alanine. It is in good agreement with theoretical prediction [20].

Variation of hardness number $H_{V}$ and

TABLE III stiffness constant $C_{11}$ with load $P$

\begin{tabular}{c|c|c|c}
\hline \hline Sample & Load $P[\mathrm{~g}]$ & $H_{V}$ & $C_{11}\left[\times 10^{14} \mathrm{~Pa}\right]$ \\
\hline \multirow{3}{*}{ L alanine } & 25 & 38.5 & 5.95 \\
& 50 & 50.4 & 9.53 \\
& 100 & 61.55 & 13.5 \\
\hline \multirow{3}{*}{ ZLA } & 25 & 33.8 & 4.738 \\
& 50 & 46.55 & 8.300 \\
& 100 & 63.9 & 14.44 \\
\hline \multirow{3}{*}{ ALA } & 25 & 49.1 & 9.100 \\
& 50 & 54.5 & 10.93 \\
& 100 & 77.7 & 20.33
\end{tabular}
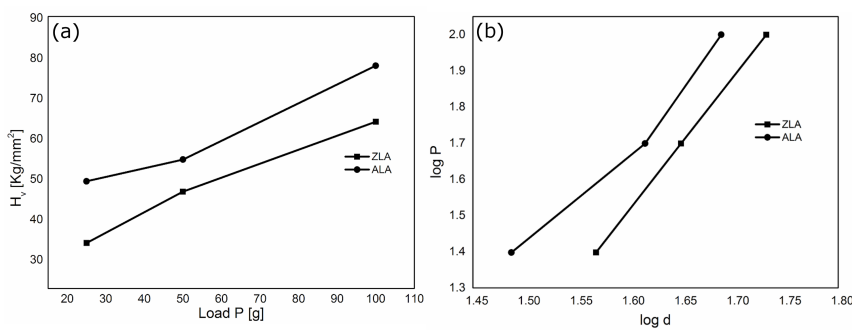

Fig. 6. Plot (a) between load $P$ and $\mathrm{H}_{V}$, (b) between $\log d$ and $\log P$.

\subsection{Dielectric studies}

The conventional parallel plate capacitor method was employed by coating the silver paste on the opposite faces 
of the crystal to establish contact between crystal and electrodes using a HIOCKI 3532-50 LCR HITESTER instrument. The variation of dielectric constant $\left(\varepsilon_{r}\right)$ and dielectric loss $(\tan \delta)$ were measured for the crystals ZLA and ALA at room temperature as a function of frequency range of $100 \mathrm{~Hz}$ to $5 \mathrm{MHz}$ (Fig. 7a and b and Fig. 8a and $\mathrm{b}$ ). Dielectric constant was calculated using the relation $\varepsilon_{r}=\frac{C t}{\varepsilon_{0} A}$, where $C$ is capacitance, $t$ is thickness of the sample, $\varepsilon_{0}=8.854 \times 10^{-12} \mathrm{~F} \mathrm{~m}^{-1}$ is permittivity of free space and $A$ is the area of cross-section.
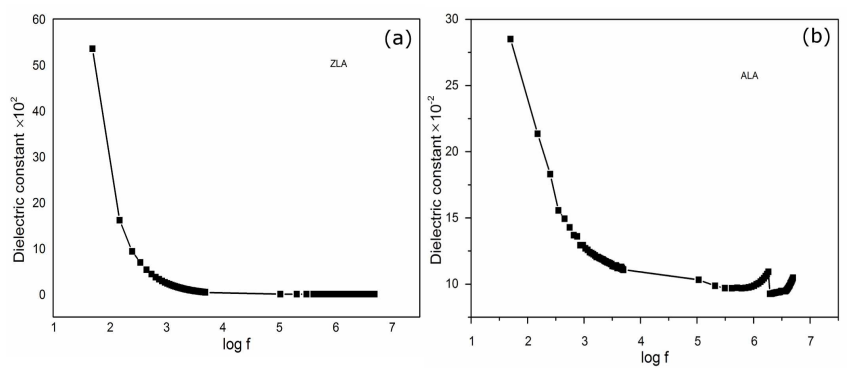

Fig. 7. Plot between $\log f$ and dielectric constant of (a) ZLA, (b) respectively for ALA.
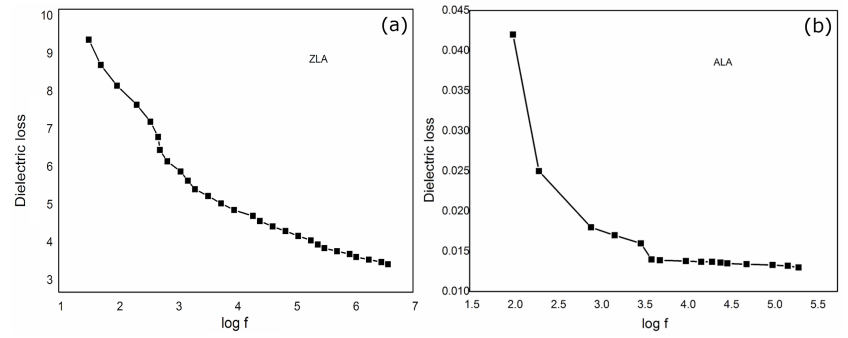

Fig. 8. Plot between $\log f$ and dielectric loss of (a) ZLA, (b) respectively for ALA.

It is seen that dielectric constant value is high at low frequencies and decreases exponentially and stabilizes. At high frequencies the electronic, ionic, dipolar, and space charge polarizations are predominant. Of all these polarizations only space charge is active at lower frequencies and there is loss of significance of other three polarizations which may lead to low value of dielectric constant at higher frequencies [28]. It is clear from Fig. 7a and b that the value of dielectric constant of the crystal ZLA is much higher than that of ALA which is an evidence for the inclusion of metal ions in to the crystal lattice. Materials with high dielectric constant at low frequency (ZLA) find applications in heating devices [29]. Due to its lower dielectric constant value, the crystal ALA finds application in the field of microelectronics [30].

The dielectric loss was also studied as a function of frequency at room temperature, as shown in Fig. 8a and b. These curves suggest that the dielectric loss strongly depends on the frequency of the applied field, similar to dielectric constant [31]. The low value of dielectric loss at high frequencies suggests that the sample enhances opti- cal quality with lesser defects and this parameter is of vital importance for NLO applications [25, 32, 33]. The nature of decrease of dielectric constant and dielectric loss with frequency suggest that the grown crystals seem to contain dipoles of continuously varying relaxation times. As the dipoles of larger relaxation times are not able to respond to the high frequencies, dielectric constant and dielectric loss are low at high frequencies [28]. The above result is in accordance with literature [11, 34]. Owing to lower dielectric constant and dielectric loss, ZLA and ALA can be preferred for use in ferroelectric and optoelectronic applications [32].

\section{Conclusion}

Good optical quality single crystals of ZLA and ALA were grown by slow evaporation solution growth method at room temperature. The dimension of ALA crystal is larger compared with ZLA crystal. Powder XRD pattern confirms the crystalline nature and from the data, various angles of reflection were found out for both the grown crystals. Single crystal XRD study established the crystal system of both these crystals as orthorhombic. From UV-visible transmission spectra, the width of transmission window is enhanced due to doping and it is more for the crystal ALA than ZLA. SHG analysis confirmed the NLO behaviour of the grown crystals. This property can be used for frequency doubling and other optical applications. The presence of various functional groups stand confirmed from FTIR spectrum. Thermal analysis proved that the crystal ALA is more stable (up to $240^{\circ} \mathrm{C}$ ) than the crystal ZLA (up to $77^{\circ} \mathrm{C}$ ). The Vickers microhardness study revealed the softness of the grown crystals and the variation of hardness coefficient and stiffness constant with load. Low dielectric constant and dielectric loss at high frequencies were ascertained through dielectric studies which paved the way to use the above crystals for ferroelectric, optoelectronic and microelectronics applications.

\section{Acknowledgments}

The authors are thankful to Indian Institute of Science, Bangalore; STIC Cochin: Bharathiar University, PSG College of Arts and Science, Sri Ramakrishna Mission Vidyalaya College of Arts and Science, Coimbatore; and St. Joseph College, Trichy for extending their facilities during the course of this study.

\section{References}

[1] X.Q. Wang, D. Xu, M. Lu, D. Yuan, J. Huang, X. Cheng, T. Xie, G.H. Zhang, S.L. Wang, S.Y. Guo, J.R. Liu, Z.H. Yang, P. Wang, J. Cryst. Growth 234, 469 (2002).

[2] X.L. Duan, D.R. Yuan, X.Q. Wang, S.Y. Guo, J.G. Zhang, D. Xu, M.K. Lu, Cryst. Res. Technol. 37, 1066 (2002). 
[3] H.L. Bhat, Introduction to Crystal Growth - Principles and Practice, CRC Press, Taylor \& Francis Group, London 2015.

[4] R. Kesavan, C. Elanchezhian, B. VijayaRamnath, Engineering Materials and Metallurgy, Anuradha Publ., 1st ed., Chennai 2011.

[5] Min-Hua Jiang, Qi Fang, Adv. Mater. 11, 1147 (1999).

[6] G. Marudhu, S. Krishnan, T. Thilak, P. Samuel, G. Vinitha, G. Pasupathi, J. Nonlinear Opt. Phys. Mater. 22, 1350043 (2013).

[7] V.G. Pahurkar, MohdAnis, M.I. Baig, S.P. Ramteke, B. Babu, G.G. Muley, Optik 142, 421 (2017).

[8] A. Puhal Raj, C. Ramachandra Raja, Spectrochim. Acta A 97, 83 (2012).

[9] J. Kishore Kumar, G. Anand, S. Gunasekaran, P. Hemalatha, S. Kumaresan, Elixir Cryst. Growth 61, 17110 (2013).

[10] S. Ummartyotin, N. Bunnak, J. Juntaro, M. Sain, H. Manuspiya, Solid State Sci. 14, 299 (2012).

[11] K. Sethuraman, R. Ramesh Babu, R. Gopalakrishnan, P. Ramasamy, Crystal Growth Des. 8, 1863 (2008).

[12] N. Vijayan, S. Rajasekaran, Bhagavannarayana, G. Ramesh BabuR, R. Gopalakrishnan, M. Palanichamy, P. Ramasamy, Cryst. Growth Des. 6, 2441 (2006).

[13] C.M. Lydia, R. Sankar, R.M. Indirani, S. Vasudevan, Mater. Chem. Phys. 114, 490 (2009).

[14] B. Shanmugam, P. Krishnamoorthy, Physica B 432 67 (2014).

[15] C.M. Lydia, S. Vasudevan, Mater. Lett. 62, 2245 (2008).

[16] Sanghyun Park, Byungkwan Song, Hoon Young Kong, Jonghoe Byun, CheongSoo Hwang, Bull. Kor. Chem. Soc. 35, 1169 (2014).

[17] R. Mohan Kumar, D. RajanBabu, D. Jayaraman, R. Jayavel, K. Kitamura, J. Cryst. Growth. 275, 1935 (2005).

[18] D. Jaikumar, S. Kalainathan, G. Bhagavannarayana, Physica B 405, 2394 (2010).
[19] K. Ambujam, S. Selvakumar, A. Prem, G. Mohamed, P. Sagayaraj, Cryst. Res. Tech. 41, 671 (2006).

[20] R. Ashok Kumar, R. Ezhil Vizhi, N. Sivakumar, N. Vijayan, D. Rajan Babu, Optik 123, 409 (2012).

[21] K. Suriya Kumar, Thenneti Raghavalu, V. Mathivanan, M. Kovendhan, B. Sivakumar, G. Ramesh Kumar, S. Gokul Raj, R. Mohan, J. Cryst. Growth 310, 1182 (2008).

[22] Net Gmelin, 1936 Handbook of Chemistry and Physics, CRC Press, 2002.

[23] V. Kannan, K. Thirupugalmani, G. Shanmugam, S. Brahadeeswaran, J. Therm. Anal. Calorim. 115, 731 (2014).

[24] S.P. Ramteke, Mohdanis, M.I. Baig, V.G. Pahurkar, G.G. Muley, Optik 137, 31 (2017).

[25] O. Sahin, O. Uzun, U. Kolemen, N. Ucar, Mater. Charact. 58, 197 (2007).

[26] Y. Wang, D.F. Eaton, Chem. Phys. Lett. 120, 441 (1985).

[27] Monita Bhat, Balwinder Kaur, Ravi Kumar, K.K. Bamzai, P.N. Kotru, B.M. Wanklyn, Nucl. Instrum. Methods Phys. Res. B 234, 494 (2005).

[28] V. Joseph, S. Gunasekaran, V. Santhanam, Bull. Mater. Sci. 26, 383 (2003).

[29] S. Suresh, D. Arivuoli, J. Miner. Mater. Character. Eng. 10, 517 (2011).

[30] M. Anis, G.G. Muley, Phys Scr. 91, 85801 (2016).

[31] C. Krishnan, P. Selvarajan, T.H. Freeda, C.K. Mahadevan, Physica B 404, 289 (2009).

[32] R. Rajasekaran, R. Mohan Kumar, R. Jayavel, P. Ramasamy, J. Cryst. Growth 252, 317 (2003).

[33] T.C. Sabari Girisun, S. Dhanuskodi, D. Mangalaraj, J. Phillip, Curr. Appl. Phys. 11, 838 (2011).

[34] Redrothu Hanumantharao, S. Kalainathan, Spectrochim. Acta Mol. Biomol. Spectrosc. 86, 80 (2012). 